\title{
An approach for the use of agricultural by-products through a biorefinery in Bangladesh
}

\author{
by M. Sarwar Jahan ${ }^{1, *}$, M. Nashir Uddin ${ }^{1}$ and A.F.M. Akhtaruzzaman²
}

\begin{abstract}
The global need for developing renewable, sustainable, biomaterials, biochemicals and biofuels continues to grow along with increasing worldwide desire to reduce fossil-fuel emissions. An appealing source for bio-based products is lignocellulosic resources, which are abundant, low cost, and are often a by-product of food production (mainly rice). This paper gives an approach for bio-based product development in Bangladesh by analyzing i) a comprehensive inventory of agricultural and lignocellulosic wastes, ii) the characteristics of these wastes, and iii) suitable methods for producing bio-based products. It is proposed that a cooperative society be set up amongst the rice producing farmers and communities. Entrepreneurs would collaborate with this cooperative society to implement the approach, and biorefinery plants could be established in different parts of the country based on the amount of available agricultural wastes in specific areas. As forest area is very limited and population density is very high in Bangladesh, wood resources cannot be utilized in biofuel, biochemicals and biomaterials production in the country, making agricultural by-products the only real option available.
\end{abstract}

Keywords: bio-based products, pulp and paper, agricultural wastes, community engagement

\section{RÉSUMÉ}

La demande mondiale pour la mise au point de biomatériaux, de produits biochimiques et de biocarburants à la fois renouvelables et durables connaît une croissance soutenue, tout comme la demande mondiale pour réduire les émissions de combustibles fossiles. Les abondantes ressources lignocellulosiques offrent une source intéressante de bioproduits à la fois peu dispendieuses et qui constituent un sous-produit de la production alimentaire (principalement celle du riz). Cet article propose une approche pour l'élaboration d'un bioproduit réalisée au Bangladesh en analysant i) l'inventaire global des résidus agricoles et lignocellulosiques, ii) les caractéristiques de ces résidus et iii) les méthodes adaptées à la production de bioproduits. Nous proposons la mise en place d'une coopérative réunissant les producteurs de riz et les collectivités. Des entrepreneurs pourraient collaborer avec cette coopérative pour la mise en œuvre de cette approche menant à la construction de bioraffineries dans différentes régions du pays en fonction de la quantité de résidus agricoles disponibles sur place. Comme il y a peu de terres boisées au Bangladesh et que la densité de population y est très forte, il n'est pas possible d'utiliser les ressources ligneuses pour la production de biocarburants, de produits biochimiques et de biomatériaux, si bien que les sous-produits agricoles demeurent la seule option possible.

Mots clés : bioproduits, pâte et papier, résidus agricoles, engagement communautaire

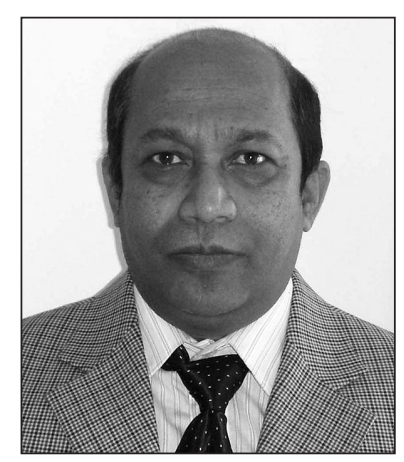

M. Sarwar Jahan

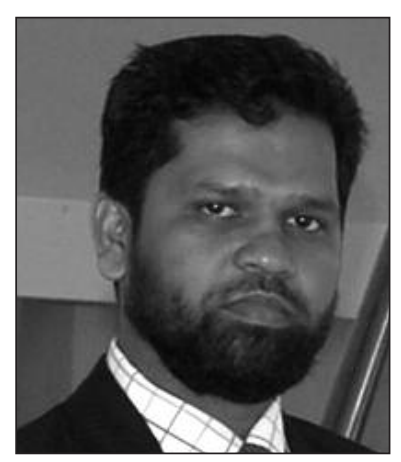

M. Nashir Uddin

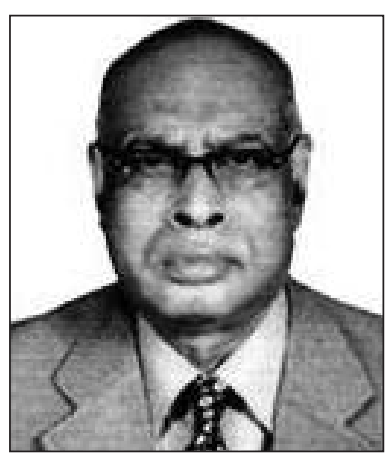

A.F.M. Akhtaruzzaman

${ }^{1}$ Pulp and Paper Research Division, BCSIR Laboratories, Dhaka, Dhaka-1205, Bangladesh; ${ }^{\star}$ corresponding author: sarwar2065@hotmail.com

${ }^{2}$ Former Director, Bangladesh Forest Research Institute, Chittagong, Bangladesh 


\section{Introduction}

Bangladesh is a densely populated country with a population of 161 million in 2015 (FAOSAT 2016) and a total area of 14.76 million ha (Kibria et al.2000). Forest lands comprise 2.53 million ha, with 1.53 million managed by the Bangladesh Forest Department (BFD). A vast area of 0.73 million ha, termed Unclassed State Forest (USF) is almost barren and is under the control the district administration of the hill districts (Akhtaruzzaman 2010). While land managed by the BFD is legally defined as forest land, a significant portion does not have any trees; tree cover amounts to $48.8 \%$ and the remaining $51.2 \%$ is denuded and degraded (Kibria et al.2000).

According to the National Forest Assessment 2005-2007, cultivated land is $56 \%$ and forest land under the management of BFD is close to $10 \%$ of the total area of Bangladesh (Altrell 2007). As shown in Table 1, 84\% of the total forest area is classified as natural forest and $16 \%$ as plantations. The two largest forest types are hill forest and mangrove forest, and together they cover more than $66 \%$ of the total forest area. Bamboo

Table 1. Forest types and area in Bangladesh (Altrell 2007)

\begin{tabular}{lll}
\hline & Forest type & $\begin{array}{l}\text { Area } \\
(\mathbf{1 0 0 0} \text { ha) }\end{array}$ \\
\hline Natural forest & Hill Forest & 551 \\
& Sal Forest & 34 \\
& Mangrove forest & 436 \\
& Bamboo/broad-leaved forest & 184 \\
& Long rotation forest plantations & 131 \\
& Short and medium rotation & 54 \\
& $\quad$ forest plantations & \\
& Mangrove plantations & 45 \\
& Rubber plantations & 8 \\
Other wooded land & Shrubs & 266 \\
& Swamps with shrubs & 23 \\
\hline
\end{tabular}

forest is about 13\% and long-rotation plantations almost 10\% of the total forest area. Short rotation plantations are about $4 \%$. Only $3 \%$ of these short rotation plantations have $3 \%-70 \%$ tree cover and $48 \%$ has 10\%-30\% tree cover (Altrell 2007). There are several reasons for low tree cover:

- Continuous pressure to convert forest lands to agricultural, as well as urbanization, industrialization, and road construction;

- Encroachment of forest land for illegal settlement is an alarming danger to the forestry sector;

- Over-exploitation of timber and fuelwood to meet the demands for a growing population;

- Shrimp cultivation along coastal areas has reduced forest cover;

- Land litigations that avert forestry activity;

- Funding and human resources are inadequate;

- Limited public understanding of forests and sustainable forestry practices; and,

- Corruption within forestry department staff.

The British government first introduced forest policies on the Indian subcontinent in 1894, which were inherited by
Bangladesh. With these policies, the conversion of forest lands to agriculture was prioritized and the preservation and conversion of resources had little consideration. After independence from British colonial rule, the Pakistan government formulated forest policies in 1955 where formal forest management planning processes, followed by inventories of different forest zones, were introduced as mandatory. The first national forest policy of independent Bangladesh was introduced in 1979. The policy was not implemented fully due to inconsistencies and contradictions. Positive impacts of this policy included a large-scale coastal mangrove plantation during the 1980s which was not managed properly due to inappropriate land tenure agreements. This new policy also extended forestry lands to the northern part of Bangladesh.

The latest forest policy was formulated in 1994 and emphasized the participation of local communities to create tree plantations outside designated forest areas. Women's participation in homestead and farm forestry was also encouraged with this policy. A target was set to make afforestation $20 \%$ of the country's land under the programs of the government and private sector by the year 2015 through active participation of the people to achieve self-reliance in forest products and maintenance of an ecological balance. Muhammed et al. $(2005,2008)$ reported that forest cover increased by only $0.14 \%$ per year, far below the targeted $0.5 \%$ in the 1994 forest policy. They considered that the policy either was not followed properly or the estimated target was unrealistic.

The 1994 policy included some initiatives for forest products. Emphasis was on the use of modern and appropriate technology at all stages of extraction and processing. The policy provided information on how modernization might ensure maximum utilization of raw materials, encouragement to grow fruit trees along with the production of timber, fuelwood, and non-wood forest products. State-owned forest industries were supposed to follow this policy to create a more competitive market and small-scale. Cottage industries were also encouraged in the rural areas but so far, no forestproduct operations have been implemented. This may be due to lack of recognizing the importance of the knowledge of technological advancement, or perhaps a lack of organization of partners that can support the policy.

The section on the biorefinery concept in this paper shows that various products can be obtained from fibrous raw materials from non-forest sources - i.e., agricultural wastes during chemical conversion. This creates an opportunity for economic growth by engaging farmers and their communities in the development of a biorefinery approach that efficiently allows the use of these wastes. It also potentially lessens the use of valuable forest resources from already depleted and marginal forest lands. Existing forest policies should be updated to reflect these opportunities.

\section{Availability of non-wood fibre in Bangladesh}

Agriculture in the country has grown at $3.2 \%$ annually in the period 1991-2005. The dominant reason for this growth has been the crop sub-sector growing at $2.3 \%$ per annum. Total food grains production, according to the Bangladesh Bureau of Statistics (BBS) in 1991-92 was 19.3 million metric tons, which has gradually increased to 29.8 million tons in 2007-08, 6.1\% higher than the previous year's production. Rice, pulses, wheat, potato, tea, maize, sugar cane, cotton, 
Table 2. Availability of important crops and waste generated in 2014 (FAOSTAT 2016)

\begin{tabular}{lll}
\hline Crops & Production $(\mathbf{M T})$ & Waste generated (MT) \\
\hline Rice & 52231000 & 78346500 \\
Wheat & 1302300 & 1953450 \\
Maize & 1525000 & 1525000 \\
Sugar cane & 4121350 & 1524900 \\
\hline Jute & 1391000 & 1391000 \\
\hline
\end{tabular}

and oilseeds are the major crops. Table 2 shows the availability of some important agricultural wastes but data are scarce. Data reported here are based on the production of crops (FAOSTAT 2016). Agricultural wastes were calculated by the ratio of crops and wastes from one acre of land. Straw is produced at the rate of 1.4-1.5 MT/ ton of grain. The main crop residue is rice straw which is mainly consumed as fodder, and is the most abundant agricultural waste (78.3 million MT), followed by wheat straw (2.0 million MT). Bagasse production after extracting juice from sugar cane is $37 \%$ or about 1.5 million MT. Maize stalks produce about 1.5 million MT. Other minor crop residues are potato and cotton stalks, rapeseed and mustard stalk. These may be used as supplementary lignocellulosic fibres.

Jute is one of the most important natural fibres in Bangladesh and has a long historical role in the socio-economic development of the country. Once it was known as the "Golden fibre of Bangladesh". The export of jute (burlap, hessian) and related products accounts for a significant portion of the total export. In addition, it provides considerable employment opportunities to the country's work force. The chemical and morphological characteristics of jute show excellent quality compared to other lignocellulosic raw materials (Jahan et al. 2007a). It has high cellulose and low lignin content, advantageous for processing. In Bangladesh, jute fibre production in 2013 was 1.4 million MT. There are many jute textile mills producing fibre products such as bags, fabrics, and rope. In such operations, the bottom part of the plant is not utilized due to inferior properties. Thus, this portion of jute removed in these mills is commonly known as jute cuttings and account for $15 \%$ of the fibres. There are strong economic and social incentives to make value-added products from jute cuttings and these wastes and industrial crops can be important raw materials for pulp and paper industries.

\section{Present status of the pulp and paper industry}

The pulp and paper industry is one of the major producers of forest products. Bangladesh Chemical Industries Corporation (BCIC) was a key player for pulp and paper production. There were four pulp and paper mills under the umbrella of BCIC, viz. Karnaphuli Paper Mill (KPM), Khulna Newsprint Mill (KNM), North Bengal Paper Mill (NBPM) and Sylhet Pulp \& Paper Mill (SPPM). Unfortunately, at present only KPM is in operation with yearly capacity of 30000 MT. This mill was commissioned in 1953. One of the main reasons that the other mills closed was due to a shortage of fibre supply. KNM, a newsprint mill, started in 1959 with an annual capac- ity of $50000 \mathrm{MT}$ and used gewa (Excoecaria agallocha L.) wood from the Sundarbans which has been declared by the $\mathrm{UN}$ as a world heritage site. Due to the restrictions on gewa, BFD stopped the supply and consequently the mill was forced to shut down. NBPM, a bagasse-based pulp mill, was commissioned in 1973 with an annual capacity of 15000 MT for writing and printing paper. However sugar production decreased remarkably and bagasse availability also decreased and led to the closure of the mill. SPPM, the only pulp mill based on reeds, began production in 1975 with an annual production of 20000 MT. With increasing limited availability of reeds, SPPM started using hardwoods which subsequently depleted and the mill was closed down. In addition, BCIC has a joint ownership on the Magura Paper Mill, which produces packaging paper at around 15000 MT per year (Quader 2011).

BCIC's pulp and paper capacity accounted for around $90 \%$ of Bangladesh's output 25 years ago. Today BCIC is producing $<5 \%$ of the total paper products in the country (Quader 2011) as private investment now dominates in the Bangladesh pulp and paper industry.

Per capita paper and board consumption is about $3.5 \sim 4.0$ $\mathrm{kg} /$ year, which is much lower than that for a typical developed country (about $300 \mathrm{~kg} /$ year/person), and substantially lower than the Asia average of around $30 \mathrm{~kg} /$ year/person. Therefore, it is desirable that there be a rapid increase of pulp and paper production in the country.

All of the new mills are using waste paper and imported market pulps. In 2014, Bangladesh imported about 162878 MT market pulp at US\$ 162.8 million, and also imported 137707 MT writing and printing paper and 352075 MT of paper board (FAOSTAT 2016). These figures create a strong case for Bangladesh needing more pulp and paper mills to reduce its dependency on imported pulp, paper and paper products. Since forest resources are already limited, alternative resources require investigation including agricultural wastes and industrial crops such as jute, kenaf, and dhaincha. These may therefore supplement traditional raw materials. The production of local pulp to reduce the dependency on imports is very important in face of the price hikes of imported pulp.

\section{The biorefinery concept}

A biorefinery is analogous to a petroleum refinery where all fractions of biomass are separated to produce fuels, valueadded chemicals and biomaterials (Amidon et al. 2008). The success of the biorefinery concept depends on the efficient utilization of all incoming bio-resources. The shift from petroleum hydrocarbons to highly oxygen-functionalized, bio-based feedstocks will create remarkable opportunities for the chemical processing industry. Biomass carbohydrates can provide a viable route to products such as alcohols, carboxylic acids, and esters. In the IFBR (integrated forest biorefinery) concept, higher value-added products such as ethanol, polymers, chemicals, carbon fibres, and liquid fuels can be produced in addition to pulp (Cabrera et al. 2016, Sun et al. 2016, Zhang et al. 2016). This concept has attracted researchers and manufacturers to devote efforts on both wood and non-wood materials (Zhu at al. 2011, Joubert et al. 2016, Kim et al. 2016). Wood resources in Bangladesh are very limited therefore we have to concentrate on non-wood based IFBR. 
In the IFBR concept, pre-treatment is an important stage where cellulose remains unaffected with limited extraction of hemicelluloses. The pre-treatment stage as a part of delignification has been claimed to enhance the digestibility of the remaining material (Al-Dajani 2008, Yoon et al. 2008, Jahan et al. 2015a,). This is strongly supported by the investigation on the pre-hydrolysis of non-wood materials (Jahan et al. 2009, 2012a, 2012b). Pre-hydrolysis reduced the chemical charge and cooking time to reach same delignification degree (Yoon et al. 2008, Jahan et al. 2015). However, an acidic pre-treatment may have a more negative effect on pulp strength properties compared to an alkaline pre-treatment, which may simultaneously enhance the impregnation of cooking alkali in the next stage (Jahan et al. 2015b). Alkaline pre-extraction of rice straw produced pulp of higher yield and strength properties compared to mild acidic extraction (Jahan et al. 2012a). Similarly, dhaincha (Sesbania bispinosa (Jacq. W. Wight) also showed better pulp yield and papermaking properties when pre-extraction was carried out with weak alkali charge (Jahan et al. 2012b).

A higher percentage of silica, hemicelluloses, and fines limit non-wood use as pulping raw materials. Thus, the difficulties in technology, economy and environment adversely affect non-wood utilization in pulp production. Pre-extraction prior to pulping agricultural wastes improved drainage resistance and increased paper machine function, and at the same time extracted hemicelluloses, lignin and acetic acid (Jahan et al. 2009, 2012b) which may be final products or raw materials for another downstream process. The pre-extraction prior to pulping removed pith from bagasse, corn stalks, and S. spontaneum (Jahan et al. 2009, Jahan and Rahman 2012b). Pith is non fibrous but chemically similar to fibre which contains cellulose, hemicelluloses and lignin (Jahan et al. 2009). Auto hydrolysis prior to pulping extracted $2 \%$ (on raw material) acetic acid and $8 \%$ sugar from corn stalks (Jahan and Rahman 2012b). Hot water extraction of rice straw extracted $15 \%$ hemicelluloses, while alkaline extraction extracted 10\% hemicelluloses (Jahan et al. 2012a). Alkaline extracted rice straw produced higher pulp yield and properties. Similarly, alkaline pre-extracted dhaincha produced better pulp yield and properties (Jahan et al. 2012b). The pre-extracted non-wood material produced pulp with improved drainage resistance and maintained yield and strength properties. Pre-hydrolysis lignin is lower in molecular weight and higher in phenolic groups (Jahan et al. 2012c), which increases the possibility of use in phenol-formaldehyde resin preparation and other phenolic resins (Wang et. al. 2012). It may be concluded that pith and high fines containing non-wood material are suitable for pulping in integrated biorefinery process.

Another approach is organic acid fractionation. Acetic acid and formic acid processes are effective alternative methods to delignify lignocellulosic materials to produce pulp for paper and cellulose (Pan and Sano 1999, Xu et al. 2006, Jahan et al. 2007a, 2007b,). The three dominant components in lignocellulosic biomass - cellulose, hemicellulose and lignin-may be effectively separated by acetic acid or formic acid in a biorefinery (Fig. 1). The pulping operation can be carried out at atmospheric pressure and the acid used easily recovered by distillation and reused in the process. Acetic acid and formic acid treatments followed by peroxy acid delignification produced pulp with higher yields and acceptable strength properties from different non-wood materials (Jahan et al. 2007a, 2007b). Organic acid lignin is an optimal feedstock for many value-added products due to its lower molecular weight and higher reactivity (Kubo et al. 1995, Wang et al. 2012). The sugars from hemicelluloses are easily converted to chemicals and fuels. Another advantage of organic acid pulping is the retention of silica on the pulp fibre that facilitates efficient recovery of cooking chemicals (Sundquist 1996, Seisto and Poppius 1997). It has been reported that organic acid delignification of rice straw followed by alkaline extraction and conventional $\mathrm{D}_{0} \mathrm{E}_{\mathrm{p}} \mathrm{D}_{1}$ bleaching produced dissolved pulp with $94 \%$ purity (Jahan et al. 2015a). In addition to dissolving pulp, silica, lignin and hemicelluloses were also separated.

The Pulp and Paper Research Division of BCSIR Laboratories has carried out extensive research on non-wood fractionation by organic acid, where cellulose, hemicelluloses, lignin and silica are separated. The fractionated biomass can be used in producing biofuels, biochemicals and biomaterials. Acetic acid and formic acid treatments followed by peroxy acid delignification produced pulp with higher yield and acceptable strength properties from different non-wood materials (Jahan et al. 2007a, 2007b). The peroxy acid de-lignified pulp showed a good bleachability on alkaline peroxide bleaching. The dissolved lignin and C-5 sugars were easily separated. Organic acid lignins have a high phenolic content with lower molecular weight that permits high reactivity with different monomers producing new polymers and new formaldehyde-free adhesive formulations (Jahan et al. 2007c). Carbon fibres can be produced from the lignin by thermal spinning followed by carbonization (Kadla et al., 2002). A fusible lignin with excellent spinnability properties to form a fine filament was produced with a thermal pre-treatment under vacuum.

The problem associated with fines and silica of non-wood pulping may be solved by the organic acid process. So it can be said that pre-extraction prior to pulping or organic acid

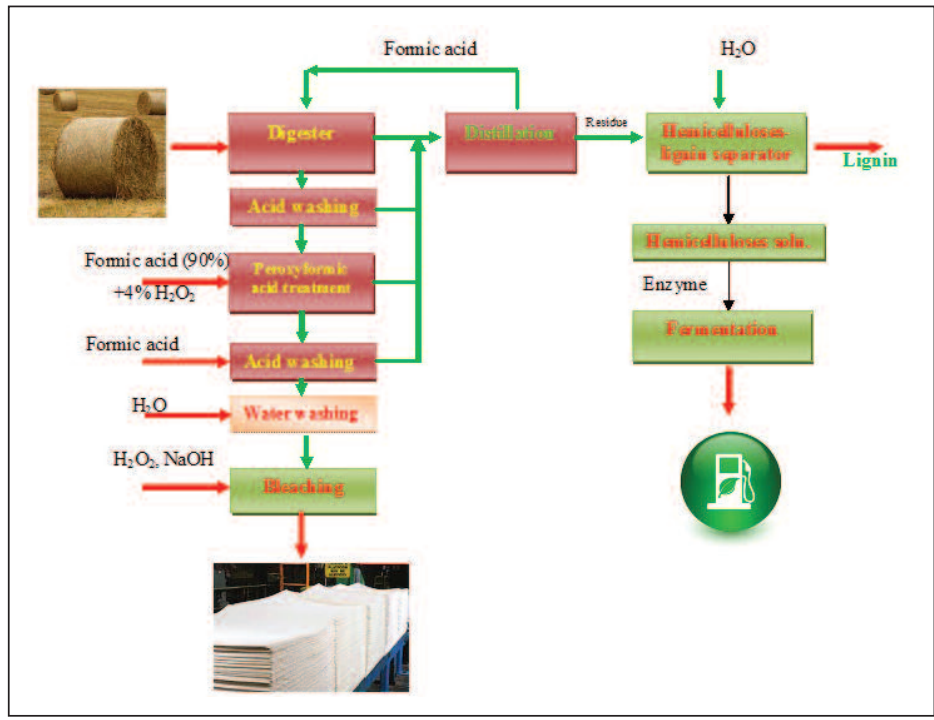

Fig. 1. Organic acid pulping of agricultural wastes in biorefinery concept 
fractionation are the best choice for non-wood pulping which integrate biorefinery. Bangladesh Forest Policy should include non-wood-based biorefinery for pulp production instead of wood.

\section{Partnerships for agricultural wastes based biorefinery}

Bio-based product development initiatives in Bangladesh should be focused on agricultural wastes. To get a sustainable supply of raw materials, farmers need to be involved in the production process. Therefore, it is required that a cooperative society among the farmers is established. This will help to smoothly run a small scale biorefinery as shown in Fig. 2.

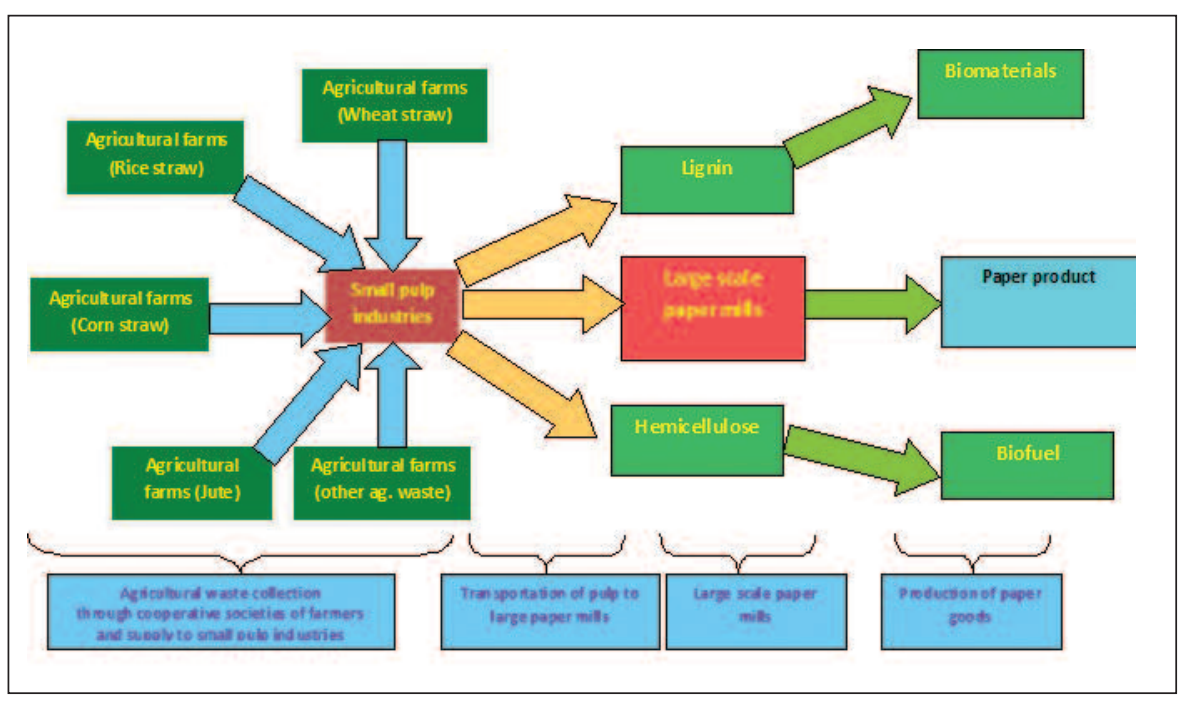

Fig. 2. Cooperative society of agricultural wastes based biorefinery is an agricultural country and generates substantial amounts of agricultural wastes. These may be alternative resources to produce bio-based products. To use agricultural resources, new technologies and strategies need to be adopted which are already developed in Bangladesh. Agricultural wastes-based IFBR can be a viable option for producing biofuel, biochemicals and biomaterials in addition to pulp. This concept can also solve problems relating to agricultural wastes pulping. Organic acid fractionation of agricultural wastes is another viable choice. To get sustainable supplies of raw materials and implement IFBR farmers need to be involved in the production process through the set up cooperatives. These strategies and technologies should be incorporated in recent forest policies. This paper briefly examined the present status in forestry in Bangladesh. The traditional forest resources in the country cannot meet the demand of the pulp and paper industries, resulting in the closing down of three main mills. However, there are many agricultural residues that can supplement forest raw materials for pulp and paper making. To this end, considerable studies have been done. There is a strong possibility of obtaining a multiple of products including pulp from the agricultural residues using the concept of a biorefinery. Still more research is warranted based on agricultural residues.
Similar cooperative societies are functioning among sugar cane farmers in India, USA and Mauritius. Entrepreneurs, preferably non-government organizations, can collaborate with the cooperative society to implement the biorefinery. Ultimately, the farmers will provide raw materials to the mill and get value for the raw material. Government policy is to increase income from agrarian products and by-products through value addition with minimum or no environmental damage. This concept will directly facilitate the farming community's economy and consequently improve livelihoods. All steps in this approach are environmentally friendly, all products and by-products are used in bio-based high-value added products, and ultimately it is expected to bring a good economic return, making important contributions to the development of local economies. In addition to pulp, bio-based products from dissolved lignin and hemicelluloses will replace petroleum products to a certain extent, which may reduce the greenhouse effect.

\section{Conclusion}

Research is ongoing all over the world to reduce greenhouse gas emissions through the viable production of biofuels, biochemicals and biomaterials from renewable resources that replace fossil fuel (Van Heiningen 2006, Wising and Stuart 2006, Xiang et al. 2015). Forest areas are limited and population density is high in Bangladesh, consequently wood resources cannot be utilized. On the other hand, Bangladesh

\section{References}

Akhtaruzzaman, A.F.M. 2010. National medium term priority framework (NMTPF)2010-2015 for Bangladesh: Sector PaperForestry. Consultancy report. FAO, Dhaka, Bangladesh

Al-Dajani, W.W. and U.W. Tschirner. 2008. Pre-extraction of hemicelluloses and subsequent kraft pulping. Part I: alkaline extraction. Tappi J. 7(6): 3-8.

Altrell, D. 2007. National forest and tree resources assessment 20052007, Bangladesh, FAO.

Amidon, T.E., C.D. Wood, A.M. Shupe, Y. Wang, M. Graves S. and Liu. 2008. Biorefinery: Conversion of woody biomass to chemicals, energy and materials. J. Biobased Mater. Bio. 2(2): 100-120.

Cabrera, M.N., M.F. Arrosbide, P. Franzoni and N. Cassella. 2016. Integrated forest biorefineries: Green liquor extraction in eucalyptus wood prior to kraft pulping. Biomass Conversion and Biorefinery $1-10$.

FAOSTAT. 2016. http://faostat3.fao.org/download/F/FO/E

Jahan, M.S., A. Al-Maruf and M.A. Quaiyyum. 2007a. Comparative studies of pulping of jute fiber, jute cutting and jute caddis. Bangladesh J. Scient. Indust. Res. 42(4): 425-434.

Jahan, M.S., D.A.N. Chowdhury and M.K. Islam. 2007b. Atmospheric formic acid pulping and TCF bleaching of dhaincha (Sesbania aculeata), kash (Saccharum spontaneum) and banana stem (Musa cavendish). Industrial Crops and Products 26(3): 324-331.

Jahan, M.S., D.A.N. Chowdhury, M.K. Islam and M.S. Islam. 2007c. Organic acid pulping of jute and its mechanism. Cellulose Chem. Technol. 41(2/3): 137-147.

Jahan, M.S., A. Saeed, Y. Niand Z. He. 2009. Pre-extraction and its impact on the alkaline pulping of bagasse. J. Biobased Mater. Bio. 3(4): 380-385. 
Jahan, M.S., M. Shamsuzzaman, M.M. Rahman, S. I. Moeiz, and Y. Ni. 2012a. Effect of pre-extraction on soda-anthraquinone (AQ) pulping of rice straw. Industrial Crops and Products, 37(1): 164-169. Jahan, M. S. and M. M. Rahman. 2012b. A biorefinery initiative in producing dissolving pulp from dhaincha (Sesbania aculeata) - a short-rotation crop. Cellulose Chem.Technol. 46(5-6): 375-380.

Jahan, M.S., Z. Liu, H. Wang, A. Saeed and Y. Ni. 2012c. Isolation and characterization of lignin from pre-hydrolysis liquor of kraftbased dissolving pulp production. Cellulose Chem. Technol. 46(34): $261-260$

Jahan, M.S., M. Sarkar and M.M. Rahman. 2015a. Sodium carbonate pre-extraction of Trema orientalis in the production of paper grade pulp. Drewno. 58(195): 69-78.

Jahan, M.S., S. Sutradhar, M. M. Rahman and M. A. Quaiyyum. 2015b. Fractionation of rice straw for producing dissolving pulp in biorefinery concept. Nord. Pulp Pap. Res. J. 30(4): 562-567.

Joubert, A.J., A.F. Chimphango and J. F. Görgens. 2016. Effect of Integrating Xylan Extraction from E. grandis into the Kraft Pulping Process on Pulp Yield and Chemical Balance. BioResources 11(1): 2417-2437.

Kadla, J.F., S. Kubo, R.A. Venditti, R.D. Gilbert, A.L. Compere and W. Griffith. 2002. Lignin-based carbon fibers for composite fiber applications. Carbon 40(15): 2913-2920.

Kim, J.S., Y.Y. Lee and T.H. Kim. 2016. A review on alkaline pretreatment technology for bioconversion of lignocellulosic biomass. Bioresource Technol. 199: 42-48.

Kibria, M.G, D.C. Sarker, M.A.T. Hossain, M.A. Mannan, M.A. Motaleb and S.S. Islam. 2000. Forest Statistic of Bangladesh, Bulletin 4, Forest Economics Division, Bangladesh Forest Research Institute, Chittagong

Kubo, S., Y. Uraki and Y. Sano. 1998. Preparation of carbon fibers from softwood lignin by atmospheric acetic acid pulping. Carbon 36 (7-8): 1119-1124.

Muhammed, N., M. Koikeand and F. Haque. 2008. Forest policy and sustainable forest management in Bangladesh: An analysis from national and international perspectives. New Forests 36(2): 201-216. Muhammed, N., M. Koike, M.D. Sajjaduzzaman and K. Sophanarith. 2005. Reckoning social forestry in Bangladesh: Policy and plan versus implementation. Forestry 78(4): 373-383.

Pan, X. J. and Y. Sano. 1999. Acetic acid pulping of wheat straw under atmospheric pressure. J. Wood Sci. 45(4): 319-325.
Quader, M.M.A. 2011. Paper sector in Bangladesh: Challenges and scope of development. J. Chem. Eng. 26 (1): 41-46.

Rathore, A. S., V.R. Chopda and J. Gomes. 2016. Knowledge management in a waste based biorefinery in the $\mathrm{QbD}$ paradigm. Bioresource Technol. http://dx.doi.org/10.1016/j.biortech.2016.03.168

Seisto, A. and K.L. Poppius. 1997. Peroxyformic acid pulping of nonwood plants by the milox method - part 1: pulping and bleaching. Tappi J. 80(9): 215-221.

Statistical Yearbook of Bangladesh. 2002. Bangladesh Bureau of Statistics. Govt. Republic of Bangladesh.

Sun, G., D. Zhang, X. An, M.S. Jahan, J. Zhou and Y. Ni. 2016. A case study for integrated forest biorefinery: Recovery of manool from evaporator condensate of a kraft pulp mill. Sep. Purif. Technol. 165: 27-31.

Sundquist, J. 1996. Chemical pulping based on formic acid: Summary of Milox research. Pap. Puu-Pap Tim. 78(3): 92-95

Van Heiningen, A. 2006. Converting a kraft pulp mill into an integrated forest biorefinery. Pulp Paper Mag. Can. 1107(6): 38-43.

Wang, H., Y. Ni, M.S. Jahan, Z. Liu and T. Schafer. 2011. Stability of cross-linked acetic acid lignin-containing polyurethane. J. Therm. Coloromet. 103(1): 293-302.

Wising, U. and P. Stuart. 2006. Identifying the Canadian forest biorefinery. Pulp Paper Mag. Can. 107(6): 25-30.

Xiang, Z., S.K. Sen, A. Roy, D. Min, D. Savithri, H. Jameel, V. Chiang and H.M. Chang. 2015. Wood characteristics and enzymatic saccharification efficiency of field-grown transgenic black cottonwood with altered lignin content and structure. Cellulose 22(1): 683-693.

Xu, F., J.X. Sun, R. Sun, P. Fowler and M.S. Baird. 2006. Comparative study of organosolvlignins from wheat straw. Indust. Crops Prod. 23(2): 180-193.

Yoon, S. H., K. Macewan and A. Van Heiningen. 2008. Hot-water pre-extraction from loblolly pine (Pinus taeda) in an integrated forest products biorefinery. Tappi J. 7(6): 27-32.

Zhang, F., D.M. Johnson and J. Wang. 2016. Integrating multimodal transport into forest-delivered biofuel supply chain design. Renew. Energ. 93: 58-67.

Zhu, J. Y., X. Zhang and X. J. Pan. 2011. Sustainable production of fuels, chemicals, and fibers from forest biomass. American Chemical Society, USA. 